\title{
Fuzzy Multicriteria Model for Selection of Vibration Technology
}

\author{
María Carmen Carnero ${ }^{1,2}$ \\ ${ }^{1}$ Technical School of Industrial Engineering, University of Castilla-La Mancha, Avenida Camilo José Cela, s/n, \\ 13071 Ciudad Real, Spain \\ ${ }^{2}$ Instituto Superior Técnico, University of Lisbon, Avenida Rovisco Pais 1, 1049-001 Lisbon, Portugal \\ Correspondence should be addressed to María Carmen Carnero; carmen.carnero@uclm.es
}

Received 6 January 2016; Revised 21 March 2016; Accepted 30 March 2016

Academic Editor: Lorenzo Dozio

Copyright (C) 2016 María Carmen Carnero. This is an open access article distributed under the Creative Commons Attribution License, which permits unrestricted use, distribution, and reproduction in any medium, provided the original work is properly cited.

\begin{abstract}
The benefits of applying the vibration analysis program are well known and have been so for decades. A large number of contributions have been produced discussing new diagnostic, signal treatment, technical parameter analysis, and prognosis techniques. However, to obtain the expected benefits from a vibration analysis program, it is necessary to choose the instrumentation which guarantees the best results. Despite its importance, in the literature, there are no models to assist in taking this decision. This research describes an objective model using Fuzzy Analytic Hierarchy Process (FAHP) to make a choice of the most suitable technology among portable vibration analysers. The aim is to create an easy-to-use model for processing, manufacturing, services, and research organizations, to guarantee adequate decision-making in the choice of vibration analysis technology. The model described recognises that judgements are often based on ambiguous, imprecise, or inadequate information that cannot provide precise values. The model incorporates judgements from several decision-makers who are experts in the field of vibration analysis, maintenance, and electronic devices. The model has been applied to a Health Care Organization.
\end{abstract}

\section{Introduction}

The benefits an organization can obtain from the use of vibration analysis include improvements in availability [1], quality [2], safety [3], cost [4, 5], and the environment. Furthermore, its versatility with regard to the machines it can be applied to and the typology of faults or anomalies that can be detected [6], along with the possibility of developing an automatic diagnostic system [7], have made it the most widely used predictive method [8]. This has led to a large number of contributions in the literature [3], analysing new diagnostic techniques $[9,10]$, many case studies of fault diagnosis in different components and types of machinery $[5,7,11,12]$, and studies of prognostics or fault prediction before it occurs [4].

To achieve all the benefits mentioned, it is essential to choose the most suitable technology for the data acquisition and handling system, so as to obtain a reliable and accurate interpretation of the signals [13], that is, reliable diagnoses. It is further recognised that the choice of a suitable measuring system is of vital importance in creating a cost-effective Condition Based Maintenance (CBM) policy [14]. However, after performing a literature review on different databases (Emerald, Hindawi, Proquest, Science Direct, and Scopus) using the terms selection vibration analyser and selection technology vibration analysis, no result was found that included a model to assist decision-making. This lack of models in vibration analysis decision-making leads to underperforming programmes characterized by a reactive approach, underuse of maintenance information systems and technologies, inaccurately managed costs, no scheduled maintenance hours, no provision for feedback on quality work, and so forth. Thus, vibration-analysis-based predictive maintenance programme managers must choose the technology to be used based only on their experience or supported by the advice of system sales staff or consultants; in those cases, the results are hard to justify to management.

This research describes an objective model using Fuzzy Analytic Hierarchy Process (FAHP) to make a choice of the most suitable technology among portable vibration analysers. The aim is to create an easy-to-use model for processing, manufacturing, services, and research organizations, to guarantee adequate decision-making in the choice of vibration 
analysis technology. This would further guarantee higher quality data acquisition, more accurate diagnosis, faster information handling, and so forth, and, overall, a more costeffective vibration analysis programme. The intention is also that the model should serve as a standard for other organizations with regard to the criteria used, the weightings associated with the criteria, and the procedures for calculating the decision model.

The model described recognises that judgements are often based on ambiguous, imprecise, or inadequate information that cannot provide precise values. It also takes into account whether the organization already has experience in applying vibration analysis and, therefore, has used a given technology before. The model incorporates judgements from several decision-makers who are experts in the field of vibration analysis, maintenance, and electronic devices. The model has been applied to a Health Care Organization.

The technology selection models which use multicriteria techniques have been widely discussed in the literature. However, this kind of modelling has not reached the field of predictive maintenance, despite being the most highly technological maintenance policy.

Therefore, this paper is intended to contribute to the use by organizations of objective models which guarantee satisfactory decision-making when acquiring vibration analysis technology.

This paper is structured as follows. Section 2 is a literature review on the application of multicriteria techniques in vibration analysis. Section 3 shows the fundamentals of FAHP. Section 4 describes the multicriteria model for assessing vibration analysers, including the structure of the model and the weighting process. Section 5 describes one example of the application of the model to a Health Care Organization. Section 6 includes the validation of the model by another fuzzy multicriteria technique and the sensitivity analysis. Section 7 sets out the practical implications of this research. Section 8 sets out the conclusions and the paper concludes with the references.

\section{Literature Review}

The choice of technology involves economic, technical, human resource, environmental, and political matters. These may need to be assessed qualitatively in many cases and that may also affect different stakeholders and present a variety of scenarios [15].

These areas may be considered by Multicriteria Decision Analysis (MCDM) techniques, which also allow objective modelling of the decision problem as one or more decisionmakers make judgements to obtain an assessment of importance of each area in the choice of predictive technology for an organization; this may guarantee acceptance by the managers of an organization of the solution proposed by the multicriteria model [15]. It also provides acceptable compromise solutions when criteria are in conflict [16], allowing the use of large quantities of data, uncertainty, relations, and objectives, aspects generally present in the real-world policy problem [17]; incorporating independent criteria into the multicriteria model guarantees no redundancy in the areas assessed. This all contributes to a considerable increase in the literature in different subjects, although in the area of maintenance it is still limited, and much more so in condition monitoring.

FAHP takes account of the uncertainty, vagueness, or ambiguous situations of the judgements given by the decision-makers $[18,19]$. Furthermore, the decision-makers prefer to use a linguistic expression rather than a crisp number because it is difficult to give an exact figure in the assessment and evaluation of decision-making problems [19]. FAHP can divide a complicated decision, with a number of conflicting criteria, into a hierarchical system of elements, facilitating the decision-making. In addition, the use of pairwise comparisons allows a ratio scale of measurement to be obtained, which leads to the generation of more precise information about the preferences of decision-makers; for this reason, it is unnecessary to define a measurement scale explicitly for each criterion [20]. It also includes a system to assess the consistency of the judgements given by the decision-makers [21], a technique which can be easily understood by managers and those ultimately responsible for accepting a decision taken.

Although there is an extensive literature reviewing the state of the art in sensors and vibration analysis instrumentation [22-26], there is a serious lack of models to facilitate taking technological decisions in vibration analysis. Only in Holbert and Lin [27] and Wang and Gao [28] is the subject analysed, but with no multicriteria model. However, these models can indeed be found in areas other than Condition Based Maintenance and vibration analysis (see, e.g., [29-34]).

Among the literature which applies MCDM to the area of decision-making in CBM are the following contributions: Carnero and Hidalgo [35] develop a system that integrates activity-based cost and analytic hierarchy process to assess the costs and benefits in a CBM policy. The criteria used are cost measurement of cost driver, time measurement of cost driver, and correlation of the cost driver with the activity cost.

Carnero [36] proposes an indicator system to control the setting up of the CBM programme, which could facilitate the early detection of anomalies during the implementation stage of the maintenance policy. Thus, it describes a predictive control of the predictive maintenance programs. The system comprises 28 indicators organized in four categories: economic evaluation, external and internal quality of the CBM, organizational structure, and evolution over time. It is held that all the indicators have similar weighting via a normalized simple additive weighting technique.

Carnero [6] sets out a model which integrates analytic hierarchy process and factor analysis in choosing diagnostic techniques and instrumentation in CBM policy. The model is used in screw compressors in which vibration analysis and lubricant analysis are applied and assessed when they are used together. Factor analysis is applied to the information supplied by the quantitative diagnostic parameters. The quantitative information resulting from the factor analysis is complemented by the qualitative information provided by other diagnostic techniques. The most significant diagnostic techniques obtained from the factor analysis and the qualitative diagnostic techniques are the alternatives incorporated into an analytic hierarchy process model described according 
to different technological levels. The decision criteria used are diagnostic quality, quantity of failures that can be analysed, cost of diagnostic technique, and supportability of the diagnostic technique.

Carnero [37] describes an assessment system which facilitates decision-making about the introduction of a CBM policy. The hierarchical structure of the problem is set out taking into account different scenarios characterized by the variables company size and productive process. Two objectives are assessed: the ability of the company to implement a $\mathrm{CBM}$ and the need for this policy in the company. The hierarchy comprises two scenario variables, 47 criteria, and these alternatives: to set up a CBM policy internally, to develop prior requisites for the setting up of a CBM policy, not to set up a CBM policy, and to outsource the policy. To integrate the results obtained from the criteria on the ability to introduce a CBM policy and the need for such a policy, a series of decision rules has been defined following the methodology of experts in rule-based systems.

Carnero [38] uses an analytic hierarchy process to choose the most appropriate predictive technique, from vibration analysis, lubricant analysis, or the integration of both techniques. The CBM policy is characterized in four levels according to the technological level. Each company is characterized using four scenario variables: typology of critical machinery in the industrial plant, technological level of the productive process in the industrial plant, number of critical machines in the industrial plant, and future behaviour of the company. Carnero [39] also chooses the condition monitoring technique to be applied, but using a multicriteria utility function and analytic hierarchy process. Discrete probability distributions are obtained for each alternative and a Monte Carlo simulation is used to calculate the final utility of the alternatives.

Bana e Costa et al. [40] describe an audit carried out via the Measuring Attractiveness by a Categorical Based Evaluation Technique for the control of a CBM policy implemented in a Health Care Organization. The model allows the performance of the CBM policy to be measured not only against each audit criterion individually, but also in each area and in overall terms. The final structure of the multicriteria audit model has 94 criteria structured in 15 areas. Integrated into a management dashboard, the model outputs permit the identification of policy deficiencies requiring urgent intervention and correction measures for its continuity. The model has been tested from data on the implementation of a CBM policy in a hospital.

\section{Fuzzy Analytic Hierarchy Process Methodology}

Analytic hierarchy process [41] is a decision-making tool to deal with complex, unstructured, and multicriteria problems. This technique provides a ranking of alternatives when all the decision criteria are considered simultaneously, by using a hierarchical structure reflecting the relationship between the goal, criteria, subcriteria, and alternatives; it also uses pairwise comparisons between the various criteria and among the alternatives with respect to each criterion; linguistic terms are used for this, associated with numerical values which
TABLE 1: Definition of fuzzy scale numbers.

\begin{tabular}{lc}
\hline Linguistic scale & Fuzzy number \\
\hline $\begin{array}{l}\text { Equally important } \\
\text { Judgement values between equally and } \\
\text { moderately }\end{array}$ & $\widetilde{1}=(1,1,1)$ \\
$\begin{array}{l}\text { Moderately more important } \\
\text { Judgement values between moderately }\end{array}$ & $\widetilde{3}=(2,3,3)$ \\
and strongly & $\widetilde{4}=(3,4,5)$ \\
$\begin{array}{l}\text { Strongly more important } \\
\text { Judgement values between strongly and }\end{array}$ & $\widetilde{5}=(4,5,6)$ \\
very strongly & $\widetilde{6}=(5,6,7)$ \\
Very strongly more important & $\widetilde{7}=(6,7,8)$ \\
Judgement values between very strongly & $\widetilde{8}=(7,8,9)$ \\
and extremely & $\widetilde{9}=(8,9,9)$ \\
\hline
\end{tabular}

constitute a scale. The scale proposed by Saaty uses integer values from one (equally important) to nine (extremely more important) and the reciprocals of these numbers [41]. A weight is calculated for each criterion (and subcriterion) based on the pairwise comparisons. The outcome of the multicriteria technique is a score for each alternative. Because the judgements are subjectively provided by the decision-maker, the consistency of these judgements has to be computed by means of a consistency index.

Saaty's scale is easy to apply, but it does not account for uncertainty (including doubt, hesitancy, vagueness, and ambiguous situations) associated with the mapping of one's judgement to a number involved in real-world decision problems [42, 43]. Also, decision-makers sometimes feel more confident giving interval judgements rather than crisp judgements $[18,44]$. Fuzzy set theory solves all these problems.

Although different fuzzy scales have been suggested, the fuzzy scale that best matches the original preference scale of the crisp analytic hierarchy process is the one shown in Table 1 [45], which will be used in this study.

Fuzzy set, membership function, and fuzzy numbers are concepts in fuzzy theory introduced by Zadeh [46]. A fuzzy set is a class of objects with a continuum of degrees of membership. This fuzzy set is characterized by a membership function, which assigns to each object a degree of membership ranging from zero to one [47]. Within the fuzzy numbers, there are triangular fuzzy numbers which allow the vagueness of the criteria analysed to be incorporated.

A triangular fuzzy number $\widetilde{a}=(l, m, u)$ is defined mathematically by the membership function $\mu_{\tilde{a}}(x): \Re \rightarrow[0,1]$ [48]:

$$
\mu_{\tilde{a}}(x)= \begin{cases}\frac{x-l}{m-l}, & \text { if } l \leq x \leq m \\ \frac{u-x}{u-m}, & \text { if } m \leq x \leq u \\ 0, & \text { otherwise, }\end{cases}
$$

where $l, m$, and $u$ are lower, median, and upper bounds of the fuzzy number and satisfy $l \leq m \leq u$. 
Kaufmann and Gupta [49] give the operational laws of triangular fuzzy numbers $\tilde{a}_{1}=\left(l_{1}, m_{1}, u_{1}\right)$ and $\tilde{a}_{2}=\left(l_{2}, m_{2}\right.$, $\left.u_{2}\right)$ :

$$
\begin{aligned}
\left(l_{1}, m_{1}, u_{1}\right) \oplus\left(l_{2}, m_{2}, u_{2}\right) & =\left(l_{1}+l_{2}, m_{1}+m_{2}, u_{1}+u_{2}\right), \\
\left(l_{1}, m_{1}, u_{1}\right) \ominus\left(l_{2}, m_{2}, u_{2}\right) & =\left(l_{1}-u_{2}, m_{1}-m_{2}, u_{1}-l_{2}\right), \\
\left(l_{1}, m_{1}, u_{1}\right) \otimes\left(l_{2}, m_{2}, u_{2}\right) & \approx\left(l_{1} l_{2}, m_{1} m_{2}, u_{1} u_{2}\right), \\
\left(l_{1}, m_{1}, u_{1}\right) \oslash\left(l_{2}, m_{2}, u_{2}\right) & \approx\left(\frac{l_{1}}{u_{2}}, \frac{m_{1}}{m_{2}}, \frac{u_{1}}{l_{2}}\right) \\
\left(l_{1}, m_{1}, u_{1}\right)^{-1} & \approx\left(\frac{1}{u_{1}}, \frac{1}{m_{1}}, \frac{1}{l_{1}}\right)
\end{aligned}
$$

for $l, m, u>0$,

$$
\begin{aligned}
& \lambda \otimes\left(l_{1}, m_{1}, u_{1}\right) \approx\left(\lambda l_{1}, \lambda m_{1}, \lambda u_{1}\right) \\
& \lambda>0, \lambda \in R^{+} .
\end{aligned}
$$

Different FAHP methods have been presented in the literature. Chang's extent analysis method [48] will be used in this study. Chang's methodology comprises the following steps $[19,45,48,50,51]$.

Step 1 (construction of hierarchy). Firstly, the important criteria are determined and structured into a hierarchy. The decision problem is aimed at the higher level of the hierarchy structure; the criteria and subcriteria are aimed at the intermediate levels and the alternatives at the lower level.

Step 2 (obtaining the fuzzy judgement matrix $\widetilde{A}$ ). This matrix has as elements the fuzzy comparison values $\widetilde{a}_{i j}$, which express the decision-maker's opinion about the relative importance of element $i$ over element $j$ at the same level of the hierarchy. The weightings between the criteria and the scale levels of each indicator are obtained from the fuzzy judgements matrix $\widetilde{A}$ :

$$
\begin{aligned}
& \widetilde{A}=\left(\tilde{a}_{i j}\right)_{n \times m} \\
& =\left[\begin{array}{cccc}
(1,1,1) & \left(l_{12}, m_{12}, u_{12}\right) & \ldots & \left(l_{1 n}, m_{1 n}, u_{1 n}\right) \\
\left(l_{21}, m_{21}, u_{21}\right) & (1,1,1) & \ldots & \left(l_{2 n}, m_{2 n}, u_{2 n}\right) \\
\vdots & \vdots & \ldots & \vdots \\
\left(l_{n 1}, m_{n 1}, u_{n 1}\right) & \left(l_{n 2}, m_{n 2}, u_{n 2}\right) & \ldots & (1,1,1)
\end{array}\right],
\end{aligned}
$$

where $\tilde{a}_{i j}=\left(l_{i j}, m_{i j}, u_{i j}\right)$ and $\tilde{a}_{i j}^{-1}=\left(1 / u_{i j}, 1 / m_{i j}, 1 / l_{i j}\right)$ for $i, j=1,2, \ldots, n$ and $i \neq j$.

To perform the pairwise fuzzy comparison, the decisionmaker uses a fuzzy scale, like that shown in Table 1.

Step 3. Calculate the value of fuzzy synthetic extent with respect to the $i$ th object from the following:

$$
\widetilde{S}_{i}=\sum_{j=1}^{m} \tilde{a}_{g_{i}}^{j} \otimes\left[\sum_{i=1}^{n} \sum_{j=1}^{m} a_{g_{i}}^{j}\right]^{-1},
$$

where $g_{i}$ are the goals of the hierarchy and $\tilde{a}_{g_{i}}^{j}$ is a triangular fuzzy number of the fuzzy comparison matrix $\widetilde{A}$ with $n$ objects and $m$ goals.

To obtain $\sum_{j=1}^{m} \widetilde{a}_{g_{i}}^{j}$, take the fuzzy sum-up of each row of the fuzzy comparison matrix $\widetilde{A}$ such that

$$
\sum_{j=1}^{m} \tilde{a}_{g_{i}}^{j}=\left(\sum_{j=1}^{m} l_{j}, \sum_{j=1}^{m} m_{j}, \sum_{j=1}^{m} u_{j}\right) .
$$

Next, take the fuzzy addition of $a_{g_{i}}^{j}(j=1,2, \ldots, m)$ values such that

$$
\sum_{i=1}^{n} \sum_{j=1}^{m} a_{g_{i}}^{j}=\left(\sum_{i=1}^{n} l_{i}, \sum_{i=1}^{n} m_{i}, \sum_{i=1}^{n} u_{i}\right) .
$$

And then compute the inverse of the vector of (11) obtaining

$$
\begin{aligned}
& {\left[\sum_{i=1}^{n} \sum_{j=1}^{m} a_{g_{i}}^{j}\right]^{-1}} \\
& \quad=\left(\frac{1}{\sum_{i=1}^{n} \sum_{j=1}^{m} u_{i j}}, \frac{1}{\sum_{i=1}^{n} \sum_{j=1}^{m} m_{i j}}, \frac{1}{\sum_{i=1}^{n} \sum_{j=1}^{m} l_{i j}}\right) .
\end{aligned}
$$

Step 4. Compute the degree of possibility of $\widetilde{S}_{2}=\left(l_{2}, m_{2}\right.$, $\left.u_{2}\right) \geq \widetilde{S}_{1}=\left(l_{1}, m_{1}, u_{1}\right)$, where $\widetilde{S}_{1}$ and $\widetilde{S}_{2}$ are given by (5). The degree of possibility between two fuzzy synthetic extents is given by

$$
V\left(\widetilde{S}_{2} \geq \widetilde{S}_{1}\right)=\sup \left[\min \mu_{\widetilde{S}_{2}}\left((y), \mu_{\widetilde{S}_{1}}(x)\right)\right]
$$

and can be expressed equivalently as follows:

$$
\begin{gathered}
V\left(\widetilde{S}_{2} \geq \widetilde{S}_{1}\right)=h g t\left(\widetilde{S}_{1} \cap \widetilde{S}_{2}\right)=\mu_{\widetilde{S}_{2}}(d) \\
= \begin{cases}1, & \text { if } m_{2} \geq m_{1} \\
0, & \text { if } l_{1} \geq u_{2} \\
\frac{l_{1}-u_{2}}{\left(m_{2}-u_{2}\right)-\left(m_{1}-l_{1}\right)}, & \text { otherwise, }\end{cases}
\end{gathered}
$$

where $d$ is the ordinate of the highest intersection point between $\mu_{\widetilde{a}_{1}}$ and $\mu_{\widetilde{a}_{2}}$ (see Figure 1). Both $V\left(\widetilde{S}_{2} \geq \widetilde{S}_{1}\right)$ and $V\left(\widetilde{S}_{1} \geq \widetilde{S}_{2}\right)$ must be computed.

Step 5. Compute the degree of possibility for a convex fuzzy number to be greater than convex fuzzy numbers $\widetilde{S}_{i}(=1,2$, ..., ) from

$$
\begin{aligned}
V & \left(\widetilde{S} \geq \widetilde{S}_{1}, \widetilde{S}_{2}, \ldots, \widetilde{S}_{k}\right) \\
& =V\left(\widetilde{S} \geq \widetilde{S}_{1}\right), V\left(\widetilde{S} \geq \widetilde{S}_{2}\right), \ldots, V\left(\widetilde{S} \geq \widetilde{S}_{k}\right) \\
& =\min V\left(\widetilde{S} \geq \widetilde{S}_{i}\right), \quad i=1,2, \ldots, k .
\end{aligned}
$$

Assuming $d^{\prime}\left(A_{i}\right)=\min V\left(\widetilde{S}_{i} \geq \widetilde{S}_{j}\right)$ for $i, j=1,2, \ldots, k, k \neq j$, the weight vector is given by

$$
W^{\prime}=\left(d^{\prime}\left(A_{1}\right), d^{\prime}\left(A_{2}\right), \ldots, d^{\prime}\left(A_{k}\right)\right)^{T} .
$$




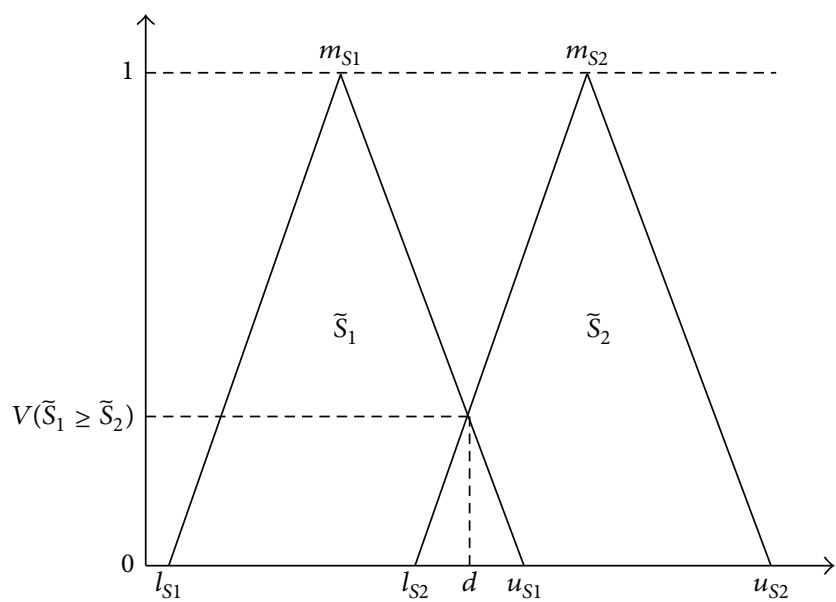

FIGURE 1: The intersection between $\widetilde{S}_{1}$ and $\widetilde{S}_{2}$.

Step 6. Compute the nonfuzzy weight vector $W$ normalizing $W^{\prime}$, which gives

$$
W=\left(d\left(A_{1}\right), d\left(A_{2}\right), \ldots, d\left(A_{k}\right)\right)^{T} .
$$

Step 7. The deviations from consistency in the judgements given are computed via the consistency index (CI) defined in the following [41]:

$$
\mathrm{CI}=\frac{\lambda_{\max }-n}{n-1}
$$

The consistency ratio (CR) is calculated from (19), in which the random consistency index (ICR) is generated by a random matrix of similar dimension to that evaluated:

$$
\mathrm{CR}=\frac{\mathrm{CI}}{\mathrm{ICR}} \text {. }
$$

If CR is less than 0.05 for a $3 \times 3$ matrix, 0.08 for a $4 \times 4$ matrix, and 0.1 for matrices of higher order, then the judgements matrix is consistent [52].

To simplify the calculation of the CR in a fuzzy environment, the crisp value $m_{i j}$ has been used [50].

\section{Fuzzy Multicriteria Model for Selection of Vibration Technology}

4.1. Structuring. The literature on vibration analysis has been used to choose the decision criteria in the model described. A variety of aspects are recommended as they deserve attention in the choice of technology [6, 53-55] and they give information from a number of suppliers of vibration analysers; the literature on the choice between different types of policy and technology not relevant to vibration analysis was also analysed $[33,56]$. Additionally, papers which assess choice of suppliers have been analysed too $[51,57,58]$. Unlike the choice of providers in the area of manufacturing, where delivery time is paramount, after-sales service is found to be a more important selection criterion than price in high-tech markets [59].

The criteria and subcriteria for vibration analyser selection proposed are as follows: (a) Hardware Characteristics (HC). These are as follows:

(i) Diagnosis Functions (DF). The field functions which the analyser could perform, such as realtime FFT, waterfalls, envelope demodulation, Spike Energy, PeakVue, time waveforms, amplitude plus phase values on speed frequency, order analysis, waveform parameters (Kurtosis and Skewness), field equilibrium in one or two planes, and automatic diagnosis tools, are looked at.

(ii) Electrical and Electronic Parameters (EP). Although the electrical and electronic features of these devices are many, a series of parameters has been chosen which can discriminate between devices: number of channels, input type (acceleration, velocity, displacement, and any nonvibration AC voltage integration (single and double full digital integration)), dynamic range, frequency range, spectrum range (useful bandwidth), spectrum lines, A/D resolution, speed range, and signal/noise ratio.

(iii) Informatics Parameters (IP). The following features are considered: processor, hard disc storage capacity, RAM storage capacity, and communication/interface system: USB, micro-SD, WiFi, Ethernet, Internet, and battery discharge time (normal operating time).

(iv) Hardware Utilities (HU). Incorporating the following additional features, which may be useful in an industrial plant, is considered: acquisition of data on preprogrammed routes, the possibility of using cloud monitoring systems, picking up sound (stethoscope), impact tests, measured in very slow machinery, lubricant control, noise analysis (thirds of an octave), and the possibility of taking photos.

All the analysers on the market include a tachometer and sensors (usually triaxial) for the gathering of data; thus, as these are not parameters that differentiate one device from another, they are not included among the aspects to assess.

(b) Software Characteristics (SC). Two areas are assessed:

(i) Software Diagnostic Functions (SDF). These functions include automatic production of a point report in alert/alarm, functions to show trends of the shadowing parameters, advance diagnostic tools for turbomachinery, analysis of temporal and spectral signals, bode, Nyquist, waterfall, and orbit.

(ii) Software Utilities (SU). Additional utilities present in the software accompanying the analyser are assessed: inspection route management and data collection, ability to incorporate other predictive techniques (thermography, ultrasound, oil analysis, electric motor analysis, vis- 
ual inspection, etc.), solutions in multiposition networks, compatibility with continuous measurement systems, production of reports, exporting to Excel or another universal format, and compatibility with different versions of Windows.

(c) Service Level (SL). This is divided into the following subcriteria:

(i) Repair and Calibration (RC). This considers the capability of the supplier to provide rapid repair and calibration services (for both the analyser and the accessories). Calibration should be possible to different standards, such as NIST and ISO10012-1 (suited to the needs of the organization) and should include an overall service of the analyser, verification of measurements and adjustment of calibration parameters, verification of deviation from nominal sensitivity of the accelerometer, checking of the sensor cable, service, and replacement of the battery if it does not pass the efficiency tests.

(ii) Warranty Period and Coverage (WPC). Both the period of the warranty and the coverage provided are taken into account, for example, inclusion of calibration services, repair of faults occurring due to normal use, coverage of spare parts, and labour and transport.

(iii) Support Service (SS). It is very important to have a support service from the supplier both for operation of the analyser and associated software and as a diagnostic service. This should all be contained in a Service Level Agreement (SLA). Within this subcriterion, two areas are assessed:

(1) Support for Hardware and Software (SHS). This includes onsite, telephone, email, and so forth, support, from the supplier or the manufacturer to solve problems related to the software which accompanies the vibration analyser; remote problem-solving assistance on the Internet; online self-help answering frequently asked questions, problem-solving manuals, application notes, and so forth; and training courses on the working of hardware and software.

(2) Support for Diagnosis and Prognosis (SDP). This diagnostic help service would, for example, allow a second opinion to be sought for specific faults, especially complex ones. This service could include the following: onsite or online assistance for problem-solving, continuous access to knowledge databases with articles, interactive services, practical guides, and so forth; access to knowledge forums with exchange of information between users and technicians; and offering training courses in vibration analysis.

(iv) After-Sales Service Utilities (ASU). This subcriterion considers additional services that the supplier may provide and which would be useful to the customer, such as extending the guarantee period, lending equipment during repairs/calibrations, flexibility in providing technical assistance (by the hour, diagnostic support vouchers), software updates for the analyser and associated software constantly adapted to industry standards, updates to hardware when required to satisfy new specifications, standards of regulations, and providing Software as a Service (SaaS) tools which allow information produced by the predictive techniques to be managed, so as to apply the predictive strategy to maintenance as efficiently as possible (ease of access to data on formats, location, time, etc.).

(d) Human Resource Parameters (HRP). Two subcriteria are assessed:

(i) Ease of Handling (EH). Ease of handling of hardware and software includes a small weighting from the analyser, the possibility of not needing wires to transfer data from the sensor, ease of handling during data acquisition, and real-time diagnosis when necessary. Integrating extra elements (cameras, stroboscopes, etc.), or elements that ensure the safety of the human resources, into the analyser itself, is also something to be considered.

(ii) Additional Training Required (ATR). If it is the first analyser purchased, a certain amount of training will be needed, which will be less if the company has already used device from the same brand, and, so, this subcriterion considers not only the training required but also the existence of prior know-how in the organization. The integration of automatic diagnostic tools is also considered.

(e) Adaptation to the Organization (AO). The adaptability of the technology to be acquired with respect to the existing hardware and software in the organization is considered. The aim is to minimize resistance to change. This includes the following:

(i) Compatibility with existing data collection and maintenance management systems (C): these systems include Computerised Maintenance Management Systems (CMMS), Enterprise Source Planning (ERP), SCADA systems, and the possibility of using cable, accelerometers, and other existing data collection devices.

(ii) Compliance with safety (CS): the device purchased should be able to be used without risk 


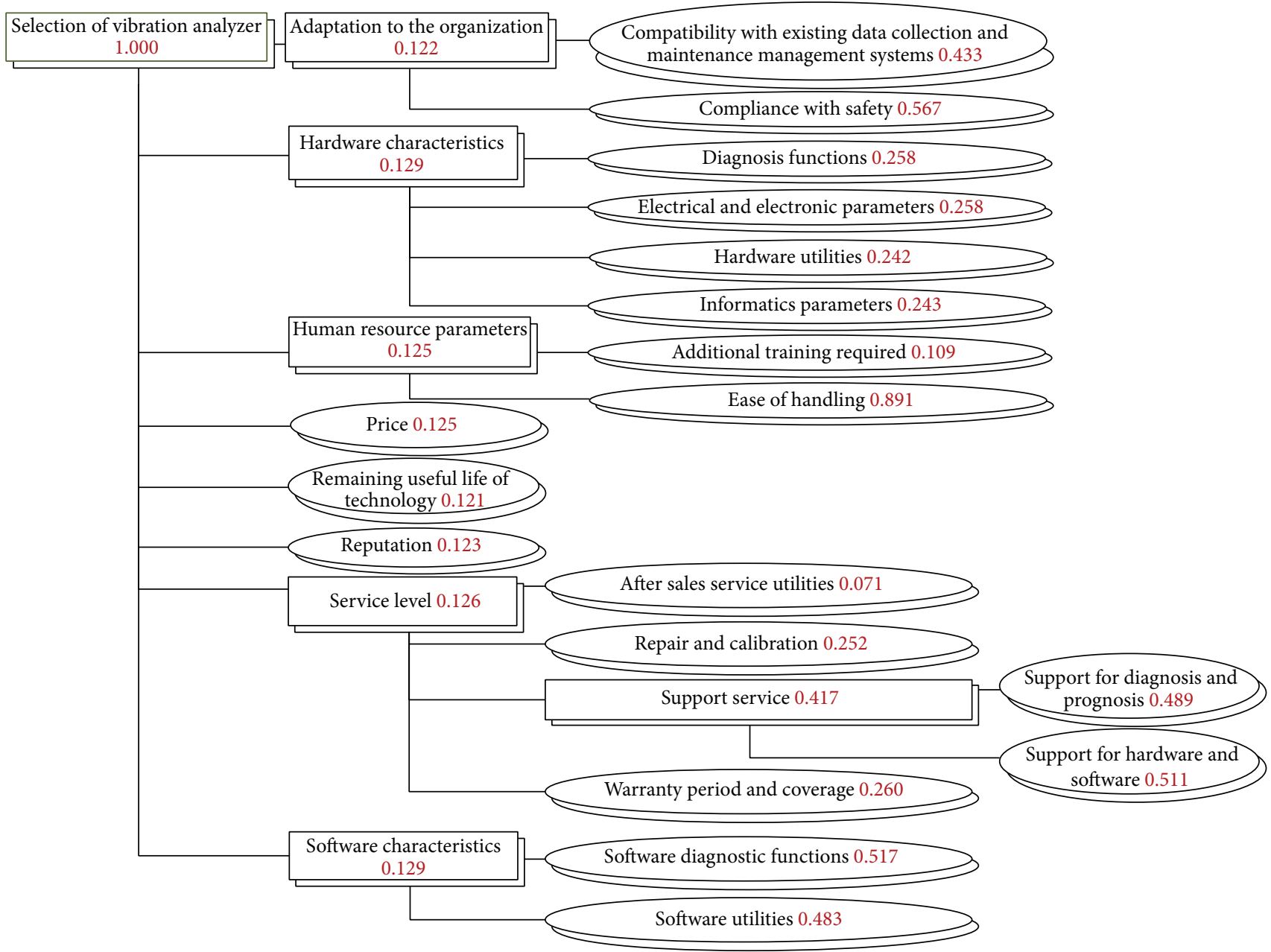

FIGURE 2: Hierarchy.

in explosive atmospheres and so should satisfy ATEX 95 (directive 94/9/EC) in the European Union or standard HAZLOC in the United States which regulates equipment and protection systems for use in potentially explosive atmospheres. There must, therefore, be a guarantee that the vibration device is certified to fulfil its purpose and has suitable information to make sure it can be used without risk.

(f) Remaining-Useful Life of Technology (RLT). The idea is to guarantee that the technology has been on the market long enough to be sure it works properly, but not so long that it could be replaced by other analyser models in the short term; this would mean that there would be no spares or update services in the short term, leading to the need to acquire new technology.

(g) Reputation $(R)$. The testimonials or references obtained from other companies are very useful when choosing a technology supplier. As well as the list of organizations where the analyzer has been used, this also includes assessments by other users from various communications systems, such as Internet forums and personal conversations. The financial situation of the supplier is included in this criterion because a solid financial situation also contributes positively to that reputation.

(h) Price (P). The price of acquisition of the analyser and associated instruments, such as sensors, cables, and stroboscopes, is assessed, along with the support services that are usually included with the analyser.

These criteria satisfy the characteristics established by Keeney [60]: exhaustive, concise, nonredundant, made operational with performance descriptors, and independent.

These criteria and subcriteria are set out in a hierarchy with the objective at the top, then the criteria, and at the bottom the subcriteria. The hierarchy of the multicriteria model is shown in Figure 2.

A descriptor has been defined for each subcriterion. A descriptor is an ordered set of possible impact levels which allows each alternative to be objectively evaluated [61]. Most of the descriptors defined in the model are qualitative and constructed. Qualitative descriptors are used when the criterion is subjective in nature or when it includes a set 
TABLE 2: Scale levels of descriptor associated with the criterion reputation.

\begin{tabular}{ll}
\hline $\begin{array}{l}\text { Level of } \\
\text { performance }\end{array}$ & $\begin{array}{l}\text { Scale levels } \\
\begin{array}{l}\text { L1 (the highest } \\
\text { level of } \\
\text { performance) }\end{array}\end{array}$ \\
\hline $\begin{array}{l}\text { The supplier has worked with more than } 20 \text { internationally recognised companies in the last } 5 \text { years. The } \\
\text { evaluations of other customers/users on Internet forums, personal conversations, and so forth are always very } \\
\text { positive. The financial situation of the supplier is acknowledged to be strong and is backed by the available } \\
\text { public information about the company. }\end{array}$ \\
$\begin{array}{l}\text { The supplier has worked with more than } 20 \text { internationally recognised companies in the last } 5 \text { years. The } \\
\text { evaluations of other customers/users on Internet forums, personal conversations, and so forth are mostly } \\
\text { positive, with small criticisms on minor matters. The financial situation of the supplier is good and is backed by } \\
\text { the available public information about the company. }\end{array}$ \\
$\begin{array}{l}\text { The supplier has worked with more than } 20 \text { internationally recognised companies in the last } 5 \text { years. The } \\
\text { evaluations of other customers/users on Internet forums, personal conversations, and so forth are mostly } \\
\text { positive, with few criticisms on matters of importance. The financial situation of the supply is unknown. }\end{array}$ \\
\hline $\begin{array}{l}\text { The supplier has worked with more than } 10 \text { internationally recognised companies in the last } 5 \text { years. The } \\
\text { evaluations of other customers/users on Internet forums, personal conversations, and so forth are mostly } \\
\text { adequate, with few criticisms on matters of importance. The financial situation of the supplier is unknown. }\end{array}$ \\
$\begin{array}{l}\text { The supplier has worked with more than } 10 \text { internationally recognised companies in the last } 5 \text { years. The } \\
\text { evaluations of other customers/users on Internet forums, personal conversations, and so forth are mostly } \\
\text { adequate, with a number of criticisms on matters of importance. The financial situation of the supplier is } \\
\text { unknown. }\end{array}$ \\
$\begin{array}{l}\text { L5 (the lowest level } \\
\text { of performance) }\end{array}$
\end{tabular}

of interrelated elementary concepts. Constructed descriptors are produced from combinations of states of several scale levels. Table 2 shows, as an example, the descriptor associated with the criterion reputation.

4.2. Weighting. The weightings of the criteria and of the scale levels for each indicator must be obtained from the fuzzy judgements matrix $\widetilde{A}$ (see (8)). To perform the fuzzy pairwise comparisons of $\widetilde{A}$, three experts in vibration analysis, maintenance, and electronic devices were asked to evaluate the importance of the criteria and subcriteria using the fuzzy scale shown in Table 1. When inconsistencies have been found in the judgements given by the experts, they have been eliminated from the model.

The geometric mean has been used to aggregate the judgements of the experts. Given the element $\widetilde{a}_{i j}=\left(l_{i j k}, m_{i j k}, u_{i j k}\right)$ as the judgements of decision-maker $k$, from comparing criterion $i$ to criterion $j$, the aggregated judgements are a triangular fuzzy number $\widetilde{D}=\left(l_{i j}, m_{i j}, u_{i j}\right)$, where [50]

$$
\begin{aligned}
& l_{i j}=\left(\prod_{k=1}^{K} l_{i j k}\right)^{1 / K}, \\
& m_{i j}=\left(\prod_{k=1}^{K} m_{i j k}\right)^{1 / K}, \\
& u_{i j}=\left(\prod_{k=1}^{K} u_{i j k}\right)^{1 / K} \\
& \quad \forall k=1,2, \ldots, K .
\end{aligned}
$$

Table 3 shows the pairwise comparison matrix for the aggregated judgements of the three experts in each criterion.
Next, the value of the fuzzy synthetic extent with respect to the $i$-object $\widetilde{S}_{i}$ is obtained; this is done by applying (9):

$$
\begin{aligned}
& \left(\sum_{i=1}^{n} \sum_{j=1}^{m} \widetilde{a}_{g_{i}}^{j}\right)^{-1} \\
& \quad=\left(\frac{1}{\sum_{i=1}^{n} \sum_{j=1}^{m} u_{i j}}, \frac{1}{\sum_{i=1}^{n} \sum_{j=1}^{m} m_{i j}}, \frac{1}{\sum_{i=1}^{n} \sum_{j=1}^{m} l_{i j}}\right) \\
& \quad=\left(\frac{1}{116.330}, \frac{1}{70.696}, \frac{1}{68.035}\right) .
\end{aligned}
$$

The values of fuzzy synthetic extents obtained are

$$
\begin{aligned}
\widetilde{S}_{\mathrm{HC}} & =\sum_{j=1}^{m} \widetilde{a}_{g_{i}}^{j} \otimes\left[\sum_{i=1}^{n} \sum_{j=1}^{m} \widetilde{a}_{g_{i}}^{j}\right]^{-1} \\
& =\left(\frac{16.177}{116.330}, \frac{21.650}{70.691}, \frac{26.819}{68.028}\right) \\
& =(0.139,0.306,0.394), \\
\widetilde{S}_{\mathrm{SC}} & =\left(\frac{14.684}{116.330}, \frac{19.506}{70.691}, \frac{24.146}{68.028}\right) \\
& =(0.126,0.276,0.355), \\
\widetilde{S}_{\mathrm{SL}} & =\left(\frac{10.288}{116.330}, \frac{14.075}{70.691}, \frac{17.868}{68.028}\right) \\
& =(0.088,0.199,0.263), \\
\widetilde{S}_{\mathrm{HRP}} & =\left(\frac{8.022}{116.330}, \frac{11.671}{70.691}, \frac{16.108}{68.028}\right) \\
& =(0.069,0.165,0.237),
\end{aligned}
$$




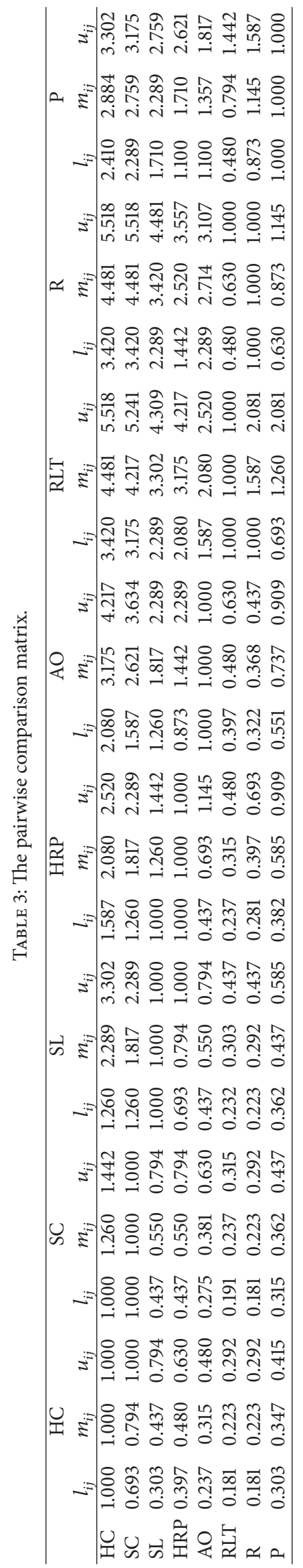




$$
\begin{aligned}
\widetilde{S}_{\text {AO }} & =\left(\frac{7.362}{116.330}, \frac{9.090}{70.691}, \frac{11.493}{68.028}\right) \\
& =(0.063,0.129,0.169), \\
\widetilde{S}_{\text {RLT }} & =\left(\frac{3.198}{116.330}, \frac{3.982}{70.691}, \frac{5.596}{68.028}\right) \\
& =(0.027,0.056,0.082), \\
\widetilde{S}_{R} & =\left(\frac{4.061}{116.330}, \frac{5.235}{70.691}, \frac{6.819}{68.028}\right) \\
& =(0.035,0.074,0.100), \\
\widetilde{S}_{\mathrm{P}} & =\left(\frac{4.236}{116.330}, \frac{5.601}{70.691}, \frac{7.481}{68.028}\right) \\
& =(0.036,0.079,0.110) .
\end{aligned}
$$

The values of fuzzy synthetic extents are compared and the degree of possibility of $V\left(\widetilde{S}_{j} \geq \widetilde{S}_{i}\right)$ is calculated using (14). However, $V\left(\widetilde{S}_{\mathrm{RLT}} \geq \widetilde{S}_{\mathrm{HC}}\right)=-0.295 ; V\left(\widetilde{S}_{\mathrm{RLT}} \geq \widetilde{S}_{\mathrm{SC}}\right)=-0.250$; $V\left(\widetilde{S}_{\text {RLT }} \geq \widetilde{S}_{\mathrm{SL}}\right)=-0.044$; in these three elements, $l_{1}-u_{2}>0$, and the elements of the matrix must be normalized [48]. A similar situation occurs in $V\left(\widetilde{S}_{\mathrm{R}} \geq \widetilde{S}_{\mathrm{HC}}\right)=-0.202 ; V\left(\widetilde{S}_{\mathrm{R}} \geq\right.$ $\left.\widetilde{S}_{\mathrm{SC}}\right)=-0.148$ and $V\left(\widetilde{S}_{\mathrm{P}} \geq \widetilde{S}_{\mathrm{HC}}\right)=-0.146 ; V\left(\widetilde{S}_{\mathrm{P}} \geq \widetilde{S}_{\mathrm{SC}}\right)=$ -0.088 .

The normalized matrix is given in Table 4 .

The values of fuzzy synthetic extents are computed again from the normalized matrix and the degrees of possibility of $V\left(\widetilde{S}_{j} \geq \widetilde{S}_{i}\right)$ are

$$
V\left(\widetilde{S}_{\mathrm{HC}} \geq \widetilde{S}_{\mathrm{SC}}\right)=1.000
$$

because

$$
m_{\mathrm{HC}} \geq m_{\mathrm{SC}}
$$

and a similar situation occurs for

$$
\begin{aligned}
& V\left(\widetilde{S}_{\mathrm{HC}} \geq \widetilde{S}_{\mathrm{SL}}\right)=1.000, \\
& V\left(\widetilde{S}_{\mathrm{HC}} \geq \widetilde{S}_{\mathrm{HRP}}\right)=1.000, \\
& V\left(\widetilde{S}_{\mathrm{HC}} \geq \widetilde{S}_{\mathrm{AO}}\right)=1.000, \\
& V\left(\widetilde{S}_{\mathrm{HC}} \geq \widetilde{S}_{\mathrm{RLT}}\right)=1.000, \\
& V\left(\widetilde{S}_{\mathrm{HC}} \geq \widetilde{S}_{\mathrm{R}}\right)=1.000, \\
& V\left(\widetilde{S}_{\mathrm{HC}} \geq \widetilde{S}_{\mathrm{P}}\right)=1.000 ; \\
& V\left(\widetilde{S}_{\mathrm{SC}} \geq \widetilde{S}_{\mathrm{HC}}\right)=\frac{0.076-0.203}{(0.144-0.203)-(0.145-0.076)} \\
& =0.992, \\
& V\left(\widetilde{S}_{\mathrm{SC}} \geq \widetilde{S}_{\mathrm{SL}}\right)=1.000, \\
& V\left(\widetilde{S}_{\mathrm{SC}} \geq \widetilde{S}_{\mathrm{HRP}}\right)=1.000,
\end{aligned}
$$

$V\left(\widetilde{S}_{\mathrm{SC}} \geq \widetilde{S}_{\mathrm{AO}}\right)=1.000$,

$V\left(\widetilde{S}_{\mathrm{SC}} \geq \widetilde{S}_{\mathrm{RLT}}\right)=1.000$,

$V\left(\widetilde{S}_{\mathrm{SC}} \geq \widetilde{S}_{\mathrm{R}}\right)=1.000$

$V\left(\widetilde{S}_{\text {SC }} \geq \widetilde{S}_{\mathrm{P}}\right)=1.000$

$V\left(\widetilde{S}_{\mathrm{SL}} \geq \widetilde{S}_{\mathrm{HC}}\right)=0.971$,

$V\left(\widetilde{S}_{\mathrm{SL}} \geq \widetilde{S}_{\mathrm{SC}}\right)=0.978$,

$V\left(\widetilde{S}_{\mathrm{SL}} \geq \widetilde{S}_{\mathrm{HRP}}\right)=1.000$,

$V\left(\widetilde{S}_{\mathrm{SL}} \geq \widetilde{S}_{\mathrm{AO}}\right)=1.000$,

$V\left(\widetilde{S}_{\mathrm{SL}} \geq \widetilde{S}_{\mathrm{RLT}}\right)=1.000$,

$V\left(\widetilde{S}_{\mathrm{SL}} \geq \widetilde{S}_{\mathrm{R}}\right)=1.000$,

$V\left(\widetilde{S}_{\mathrm{SL}} \geq \widetilde{S}_{\mathrm{P}}\right)=1.000 ;$

$V\left(\widetilde{S}_{\mathrm{HRP}} \geq \widetilde{S}_{\mathrm{HC}}\right)=0.959$,

$V\left(\widetilde{S}_{\mathrm{HRP}} \geq \widetilde{S}_{\mathrm{SC}}\right)=0.966$,

$V\left(\widetilde{S}_{\mathrm{HRP}} \geq \widetilde{S}_{\mathrm{SL}}\right)=0.986$,

$V\left(\widetilde{S}_{\mathrm{HRP}} \geq \widetilde{S}_{\mathrm{AO}}\right)=1.000$,

$V\left(\widetilde{S}_{\mathrm{HRP}} \geq \widetilde{S}_{\mathrm{RLT}}\right)=1.000$,

$V\left(\widetilde{S}_{\mathrm{HRP}} \geq \widetilde{S}_{\mathrm{R}}\right)=1.000$,

$V\left(\widetilde{S}_{\mathrm{HRP}} \geq \widetilde{S}_{\mathrm{P}}\right)=0.993 ;$

$V\left(\widetilde{S}_{\mathrm{AO}} \geq \widetilde{S}_{\mathrm{HC}}\right)=0.945$,

$V\left(\widetilde{S}_{\mathrm{AO}} \geq \widetilde{S}_{\mathrm{SC}}\right)=0.952$,

$V\left(\widetilde{S}_{\mathrm{AO}} \geq \widetilde{S}_{\mathrm{SL}}\right)=0.972$,

$V\left(\widetilde{S}_{\mathrm{AO}} \geq \widetilde{S}_{\mathrm{HRP}}\right)=0.986$,

$V\left(\widetilde{S}_{\mathrm{AO}} \geq \widetilde{S}_{\mathrm{RLT}}\right)=1.000$,

$V\left(\widetilde{S}_{\mathrm{AO}} \geq \widetilde{S}_{\mathrm{R}}\right)=0.993$,

$V\left(\widetilde{S}_{\mathrm{AO}} \geq \widetilde{S}_{\mathrm{P}}\right)=0.979 ;$

$V\left(\widetilde{S}_{\mathrm{RLT}} \geq \widetilde{S}_{\mathrm{HC}}\right)=0.934$,

$V\left(\widetilde{S}_{\mathrm{RLT}} \geq \widetilde{S}_{\mathrm{SC}}\right)=0.940$,

$V\left(\widetilde{S}_{\mathrm{RLT}} \geq \widetilde{S}_{\mathrm{SL}}\right)=0.960$,

$V\left(\widetilde{S}_{\mathrm{RLT}} \geq \widetilde{S}_{\mathrm{HRP}}\right)=0.974$,

$V\left(\widetilde{S}_{\mathrm{RLT}} \geq \widetilde{S}_{\mathrm{AO}}\right)=0.986$, 


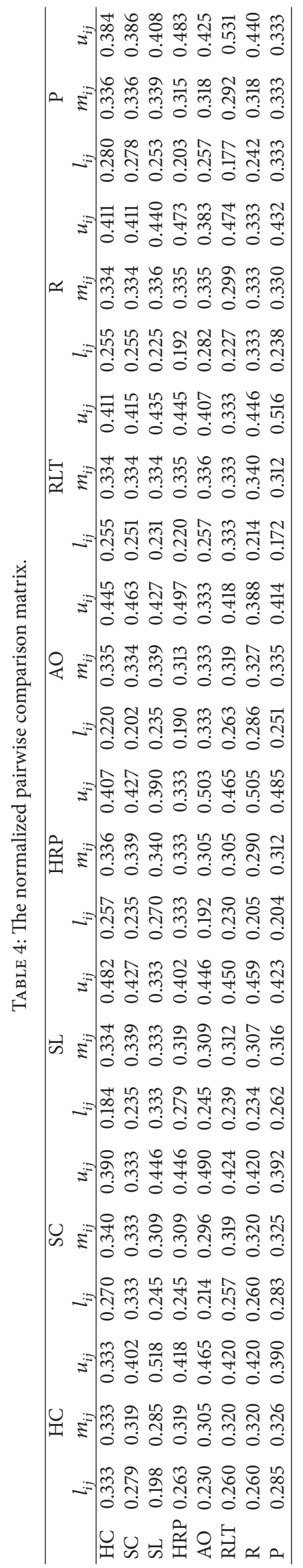




$$
\begin{aligned}
& V\left(\widetilde{S}_{\mathrm{RLT}} \geq \widetilde{S}_{\mathrm{R}}\right)=0.979, \\
& V\left(\widetilde{S}_{\mathrm{RLT}} \geq \widetilde{S}_{\mathrm{P}}\right)=0.966 ; \\
& V\left(\widetilde{S}_{\mathrm{R}} \geq \widetilde{S}_{\mathrm{HC}}\right)=0.951, \\
& V\left(\widetilde{S}_{\mathrm{R}} \geq \widetilde{S}_{\mathrm{SC}}\right)=0.958, \\
& V\left(\widetilde{S}_{\mathrm{R}} \geq \widetilde{S}_{\mathrm{SL}}\right)=0.979, \\
& V\left(\widetilde{S}_{\mathrm{R}} \geq \widetilde{S}_{\mathrm{HRP}}\right)=0.993, \\
& V\left(\widetilde{S}_{\mathrm{R}} \geq \widetilde{S}_{\mathrm{AO}}\right)=1.000, \\
& V\left(\widetilde{S}_{\mathrm{R}} \geq \widetilde{S}_{\mathrm{RLT}}\right)=1.000, \\
& V\left(\widetilde{S}_{\mathrm{R}} \geq \widetilde{S}_{\mathrm{P}}\right)=0.986 ; \\
& V\left(\widetilde{S}_{\mathrm{P}} \geq \widetilde{S}_{\mathrm{HC}}\right)=0.964 \\
& V\left(\widetilde{S}_{\mathrm{P}} \geq \widetilde{S}_{\mathrm{SC}}\right)=0.971, \\
& V\left(\widetilde{S}_{\mathrm{RLT}} \geq \widetilde{S}_{\mathrm{SL}}\right)=0.993, \\
& V\left(\widetilde{S}_{\mathrm{RLT}} \geq \widetilde{S}_{\mathrm{HRP}}\right)=1.000, \\
& V\left(\widetilde{S}_{\mathrm{RLT}} \geq \widetilde{S}_{\mathrm{AO}}\right)=1.000, \\
& V\left(\widetilde{S}_{\mathrm{RLT}} \geq \widetilde{S}_{\mathrm{R}}\right)=1.000 \\
& \mathrm{P}
\end{aligned}
$$

The minimum degrees of possibility of the model are

$$
\begin{aligned}
\min V\left(\widetilde{S}_{\mathrm{HC}} \geq \widetilde{S}_{i}\right) & =1.000 ; \\
\min V\left(\widetilde{S}_{\mathrm{SC}} \geq \widetilde{S}_{i}\right) & =0.993 ; \\
\min V\left(\widetilde{S}_{\mathrm{SL}} \geq \widetilde{S}_{i}\right) & =0.973 ; \\
\min V\left(\widetilde{S}_{\mathrm{HRP}} \geq \widetilde{S}_{i}\right) & =0.962 ; \\
\min V\left(\widetilde{S}_{\mathrm{AO}} \geq \widetilde{S}_{i}\right) & =0.946 ; \\
\min V\left(\widetilde{S}_{\mathrm{RLT}} \geq \widetilde{S}_{i}\right) & =0.935 ; \\
\min V\left(\widetilde{S}_{\mathrm{R}} \geq \widetilde{S}_{i}\right) & =0.952 ; \\
\min V\left(\widetilde{S}_{\mathrm{P}} \geq \widetilde{S}_{i}\right) & =0.964 .
\end{aligned}
$$

The weighting vector $W^{\prime}$ (see (13)) is

$$
\begin{aligned}
& W^{\prime} \\
& =(1.000,0.993,0.973,0.962,0.946,0.935,0.952,0.964)^{T} .
\end{aligned}
$$

After normalizing, the nonfuzzy weighting vector $W$ is

$$
\begin{aligned}
& W(\mathrm{HC}, \mathrm{SC}, \mathrm{SL}, \mathrm{HRP}, \mathrm{AO}, \mathrm{RLT}, \mathrm{R}, \mathrm{P}) \\
& =(0.129,0.129,0.126,0.125,0.122,0.121,0.123,0.125) .
\end{aligned}
$$

The CR is calculated from (19) to evaluate deviations from consistency in the judgements of the pairwise comparison matrix among the criteria, giving 0.000 .

A similar calculation process is followed with the pairwise comparison matrix between the subcriteria. Because some elements in the pairwise comparison matrix of aggregated judgements between the subcriteria included in the criterion hardware characteristics have $V\left(\widetilde{S}_{2} \geq \widetilde{S}_{1}\right)<0$, that is, $l_{1}-u_{2}>$ 0 , the elements of the matrix must be normalized. Thus, after normalization of the pairwise comparison matrix of aggregated judgements, the resulting nonfuzzy weighting vector is

$$
W(\mathrm{DF}, \mathrm{EP}, \mathrm{IP}, \mathrm{HU})=(0.258,0.258,0.243,0.242) .
$$

The remaining nonfuzzy weighting vectors are

$$
W(\mathrm{SDF}, \mathrm{SU})=(0.517,0.483)
$$

after normalization of the pairwise comparison matrix of aggregated judgements:

$$
W(\mathrm{EH}, \mathrm{ATR})=(0.891,0.109) \text {. }
$$

Consider $W(\mathrm{SS}, \mathrm{WPC}, \mathrm{RC}, \mathrm{ASU})=(0.417,0.260,0.252$, 0.071); in this case, the judgements of only two decisionmakers have been taken into account since the third showed a high level of inconsistency.

Consider $W($ SHS, SDP $)=(0.511,0.489)$, after normalization of the pairwise comparison matrix of aggregated judgements. Consider

$$
W(\mathrm{C}, \mathrm{CS})=(0.433,0.567) \text {. }
$$

All the pairwise comparison matrices between the subcriteria have given $\mathrm{CR}=0.000$, which guarantees the consistency of the judgements given.

Utility functions have been applied between the scale levels of the subcriteria. If the scale levels $\left(x_{i}\right)$ of a criterion/subcriterion can vary from the highest level of performance (L1) to the worst level of performance (L5), the utilities $u_{i}$, associated with these levels, range from 1 to 0 , respectively, evaluating all the descriptors on a homogenous scale.

\section{Case Study}

The benefits of vibration analysis are even more relevant in Health Care Organization because the quality of maintenance given can affect the lives of patients or even a whole community [33]; things like avoiding the interruption of diagnostic services, patient visits, treatments, and safe care of patients and visitors to the centre are important to the community. Thus, the benefits of vibration analysis have a strong social influence in that a failure can cause incalculable losses (of life, or by worsening the condition of patients). Although 


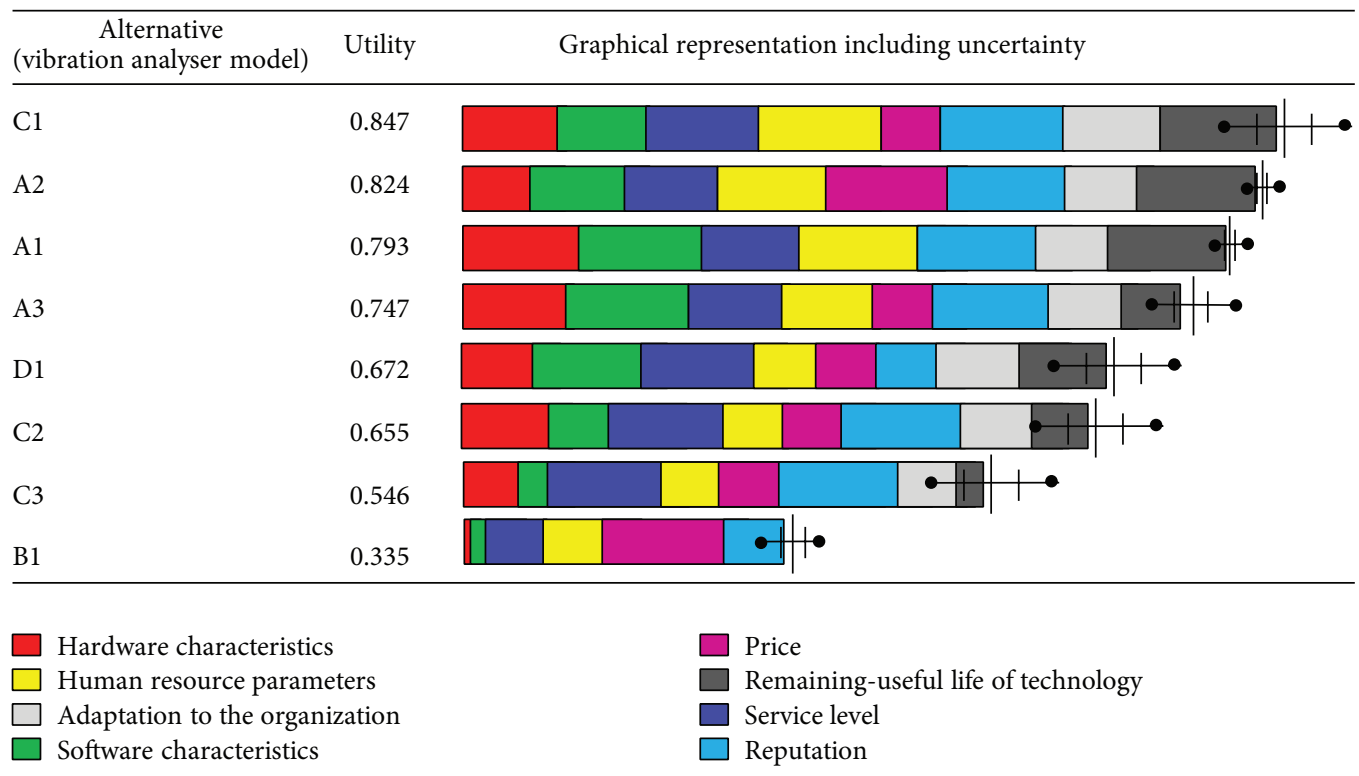

FIgURE 3: Results.

this is clear in medical equipment, it can also be extended to conventional facilities within Health Care Organizations.

The case study we are concerned with assesses the capacity of noninterference with other devices for collection and medical treatment. A Health Care Organization also stores a large quantity of gases and chemicals which could cause explosions, as well as chemical, biological, radiological, and nuclear equipment; therefore, an intrinsically safe data collector is necessary for hazardous locations.

For the introduction of a programme based on vibration analysis in a Health Care Organization, eight vibration analyser models were assessed, three analysers belonging to one supplier and two different manufacturers (identified as A1, $\mathrm{A} 2$, and $\mathrm{A} 3$ ); one analyser belonging to a manufacturer identified as B1; three analysers belonging to one manufacturer and identified as $\mathrm{C} 1, \mathrm{C} 2$, and C3; and one analyser model from a manufacturer identified by the code D1. The brands and models of the analysers are not given, so as not to include information that could be considered as publicity for a specific brand and also to guarantee the confidentiality of the study. A valuation is assigned to each alternative at one of the scale levels available for each descriptor. For some analysers, the information obtainable was incomplete or unsuited to assessing some descriptors; to solve this, probability distributions were used, which allow the model to be assessed from the most probable values.

The model enabled the results shown in Figure 3 to be obtained.

The results show that although price is something to be borne in mind, it is not decisive when choosing a vibration analyser, as the increase in price is compensated for in a very important way by an increase in diagnostic capacity and the support provided. It can also be seen that the technological level is very high, with the most recent available analysers including asset management systems, which involves full management of the machinery and not just detection and diagnosis of breakdowns. Automatic diagnosis and the inclusion of wireless utility and different communication systems are facets which distinguish the most recent analysers from those that have already been available for some years.

\section{Testing of the Model}

To guarantee the robustness of the model, a sensitivity analysis was performed. This analysis modifies the weightings assigned to the model criteria coherently, to assess the changes which appear in the ranking of alternatives. All the weightings of the criteria have been modified, increasing or decreasing them by $5 \%$. In no case is there any change in the analyser chosen in the first place and the rest of the ranking is also unchanged, with only two exceptions. When the weighting is decreased in the criterion price to $9 \%$ or less (its weighting was originally $12.5 \%$ ), there is a switch in the classification of the alternatives in second and third place, as can be seen in Figure 4 . Nonetheless, it is felt that the criterion price should not be valued with weightings of $9 \%$ or below. When the weighting is increased in the criterion remaining-useful life of the technology, the alternatives in fifth and sixth places switch positions. Therefore, the model is robust as in no case is there a switch in the position of an alternative chosen as ideal; also, the complete ranking of alternatives is unaltered when the other weightings of the criteria are modified, with the two exceptions mentioned.

The multicriteria model Fuzzy Technique for Order of Preference by Similarity to Ideal Solution (FTOPSIS) developed in the crisp mode by Hwang and Yoon [62] and whose extension to the fuzzy environment was described by Chen [63] was also used to test the method. This technique was chosen because it is widely and successfully used in the literature [64]; it is also easy to apply and understand and it is a technique which is not limited by human capacity restrictions and therefore can be used with a large number of 


\begin{tabular}{|c|c|c|}
\hline $\begin{array}{c}\text { Alternative } \\
\text { (vibration analyser model) }\end{array}$ & Utility & Graphical representation including uncertainty \\
\hline $\mathrm{C} 1$ & 0.861 & \\
\hline A1 & 0.825 & \\
\hline A2 & 0.817 & \\
\hline A3 & 0.757 & \\
\hline D1 & 0.679 & \\
\hline $\mathrm{C} 2$ & 0.661 & \\
\hline $\mathrm{C} 3$ & 0.548 & $01 \mid+$ \\
\hline B1 & 0.309 & \\
\hline
\end{tabular}

Hardware characteristics

Human resource parameters

Adaptation to the organization

Software characteristics

Price

$\square$ Remaining-useful life of technology

Service level

$\square$ Reputation

\begin{tabular}{lcc}
\hline Criteria & Weightings (\%) & Graphical representation \\
\hline Hardware characteristics & 13.4 \\
Software characteristics & 13.4 \\
Service level & 13.2 \\
Human resource parameters & 13.0 \\
Adaptation to the organization & 12.7 & \\
Support service & 5.5 & \\
Price & 9.0 \\
Reputation & 12.8 & \\
Remaining-useful life of the technology & 12.6 &
\end{tabular}

FIGURE 4: Results of the sensitivity analysis when the weighting of price is decreased.

criteria and alternatives [65]. Plus, it is a technique regularly used in the literature to compare and validate FAHP. The main idea of the method is that the chosen alternative should have the shortest Euclidean distance from the positive-ideal solution and the longest distance from the negative-ideal solution [66].

Applying the procedure described by Chen [63] gives the distances of each analyser assessed with respect to the fuzzy positive-ideal solution $\left(d_{i}^{+}\right)$and from the fuzzy negative-ideal solution $\left(d_{i}^{-}\right)$. The closeness coefficient of each alternative or the degree of fuzzy satisfaction of each alternative was also calculated. The results obtained are shown in Table 5.

To compare variance in the decisions, the FAHP and FTOPSIS were plotted on the same scale, by rescaling the performance values obtained by each vibration analyser to the same scale such that the normalized sum equals 1 . Figure 5 presents the results of the comparative ranking indices. Figure 5 shows that the results given by the two techniques are very close. Both techniques give analyser $\mathrm{C} 1$ as the best alternative; furthermore, both techniques give the same position for five of the eight analysers tested, and there were no relevant changes in the three remaining alternatives.

The result given by the model is considered appropriate for the Health Care Organization since it involves equipment with very high specifications in support material for
TABLE 5: Distances of each alternative from the fuzzy positive- and negative-ideal solution and closeness coefficient.

\begin{tabular}{lcccc}
\hline Alternatives & $d_{i}^{+}$ & $d_{i}^{-}$ & $\begin{array}{c}\text { Closeness } \\
\text { coefficient }\end{array}$ & Ranking \\
\hline A1 & 17.1503 & 0.9194 & 0.0509 & 2 \\
A2 & 17.1524 & 0.9098 & 0.0504 & 4 \\
A3 & 17.1651 & 0.9126 & 0.0505 & 3 \\
B & 17.6708 & 0.3783 & 0.0210 & 8 \\
C1 & 17.1528 & 0.9229 & 0.0511 & 1 \\
C2 & 17.3703 & 0.7116 & 0.0394 & 6 \\
C3 & 17.4322 & 0.6545 & 0.0362 & 7 \\
D & 17.2194 & 0.8610 & 0.0476 & 5 \\
\hline
\end{tabular}

diagnosis and knowledge of hardware and software; this is very useful for an organization that is beginning to apply vibration analysis. It can also be easily transported and used by nonexpert human resources, as it has safety features to prevent staff catching on any moving parts. It is new on the market and is compatible with IT systems for data collection and handling already available to Health Care Organizations and which satisfy the electromagnetic safety requirements of these facilities. The analyser has high diagnostic capacity, but 


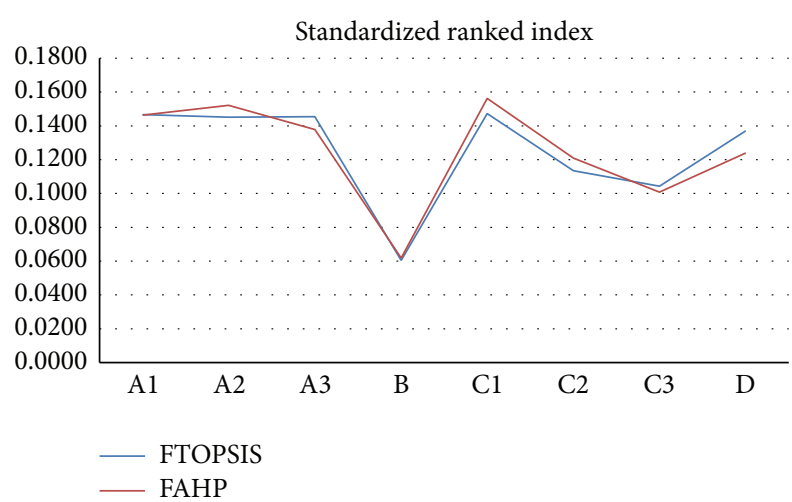

FIGURE 5: Comparison of vibration analyser results from FAHP and FTOPSIS.

it is not the best of those assessed in this regard; this is because it is preferable to have more intuitive equipment which can diagnose the most common anomalies in the organization, rather than the most innovative diagnostic techniques, but which cannot be understood by staff due to their complexity. The price is medium-high, but this is partly compensated for by the high storage capacity, by both internal and external auxiliary systems; this avoids having to perform shortcuts or download the data at frequent intervals. The additional training required by staff is more limited than that for the other alternatives, minimizing training costs. Thus, the alternative given by the model is considered appropriate to the needs of the organization.

\section{Practical Implications}

This model may prove helpful for the maintenance managers of these organizations in choosing the technology best suited to the needs of the organization. It could also be used by those in charge of research projects or institutions who need to acquire vibration analysis technology. The practical implications of this research are as follows:

(i) To guarantee the success of vibration analysis programmes. Choosing the right technology guarantees a higher quality in data acquisition, more accurate diagnosis, greater speed in handling information, and so forth, and, in summary, a cost-effective vibration analysis programme. This means that it is not necessary to eliminate large numbers of vibration analysis programmes after a short time or to use them very little.

(ii) To have an easy reference model for the use of MCDM techniques for choice in technology. This would facilitate real application to other organizations as it would be possible to replicate the procedures and calculations carried out in this study.

(iii) To be a reference for the decision criteria that could be used in the choice of technology. Some criteria could be adapted to the final aims of each organization or could introduce some others. Nevertheless, the criteria proposed would make the task of applying or adapting this research to other organizations easier.

(iv) To use an objective mathematical model which justifies decisions about technology acquisition to management or those who head the organizations, universities, research institutes, and so forth.

(v) To encourage the use of participative models in the choice of vibration technology. Experts in vibration analysis within an organization, who are also the users of the equipment, can be involved in creating the model; they can do this by providing the judgements for the pairwise comparison matrices. This guarantees that the users will subsequently be satisfied when using the vibration analyser that they have chosen themselves through the model.

(vi) To design a model which incorporates the uncertainties, hesitancy, and ambiguities which are part of human decision-making.

The final aim is that the choice of technology should efficiently improve the life cycle of the machines and devices it controls. It also makes it easy to achieve business aims: an increase in production (availability), quality, safety, reduction in delivery time, reduction in costs, and so forth may lead to competitive advantages.

In the case of universities and research centres, a suitable choice of technology can guarantee data acquisition adapted to need, make the work of researchers easier, and finally give results of greater precision and quality.

Given the lack of models like that described in this paper in the literature, it is hoped that the model will stimulate more such work on this kind of decision-making.

\section{Conclusions}

Despite the importance of the choice of technology for the acquisition of reliable data and the best diagnosis, decision support models as described in the literature are nonexistent. The people, therefore, who are responsible for this decision can find problems in developing objective decision-making which they can justify to the managers of the organization.

This research shows an easy-to-use model for processing, manufacturing, services, and research organizations, to guarantee adequate decision-making in the choice of vibration analysis technology. This would further guarantee higher quality data acquisition, more accurate diagnosis, faster information handling, and so forth, and, overall, a more cost-effective vibration analysis programme. The intention is also that the model should serve as a standard for other organizations with regard to the criteria used, the weightings associated with the criteria, and the procedures for calculating the decision model.

The model was constructed by a Fuzzy Analytic Hierarchy Process which allows the inclusion of the uncertainties and ambiguities that form part of the decision processes. In building the model, judgements given by three decision-makers, experts in vibration analysis, maintenance, and electronic devices, were used. These judgements allow weightings to be 
obtained and associated with the criteria and subcriteria that form part of the model. The model allows different vibration analysers models to be assessed, thanks to the definition of descriptors with different scale levels characterizing the level of performance of a criterion or subcriterion from highest to lowest.

The model thus obtained is validated by the use of the FTOPSIS technique and gives as the best alternative the same vibration analysis model as that given by FAHP. The other alternatives give very similar values for both techniques. A sensitivity analysis was also carried out which guarantees the stability of the result with respect to small variations in the weightings assigned to the criteria and subcriteria.

This paper is intended to contribute to the use by organizations of objective models which guarantee satisfactory decision-making when acquiring vibration analysis technology. To do this, it describes an example of the application of the model to a Health Care Organization, which generally lacks programmes based on vibration analysis, unlike other processing and manufacturing plants. Different models of vibration analyser have been assessed, from different manufacturers and suppliers, looking at the characteristics of the Spanish market, and a complete classification of the alternatives is obtained.

This model is useful not only in manufacturing, energy, processing plants, and service companies, but also in universities and research centres, which have to purchase vibration analysers for teaching and research. With a focus on teaching or research, it would be necessary to adjust the weightings of the criteria and subcriteria to the needs of the organization in each case, but the model is still useful.

Given the lack of models like that described in this paper in the literature, it is hoped that the model will stimulate more such work on this kind of decision-making.

\section{Competing Interests}

The author declares no competing interests.

\section{Acknowledgments}

This research is supported by the Junta de Comunidades de Castilla-La Mancha and the European Regional Development Fund (ERDF) within Project PPII-2014-013-P.

\section{References}

[1] H. M. Bari, A. A. Deshpande, and S. S. Patil, "Availability improvement by early detection of motor bearing failure using comprehensive condition monitoring techniques at DTPS," in Vibration Engineering and Technology of Machinery: Proceedings of VETOMAC X 2014, held at the University of Manchester, UK, September 9-11, 2014, J. K. Sinha, Ed., vol. 23 of Mechanisms and Machine Science, pp. 1101-1111, Springer, Berlin, Germany, 2015.

[2] C. López-Escobar, R. González-Palma, D. Almorza, P. Mayorga, and M. C. Carnero, "Statistical quality control through process self-induced vibration spectrum analysis," International Journal of Advanced Manufacturing Technology, vol. 58, no. 9-12, pp. 1243-1259, 2012.
[3] R.-E. Precup, P. Angelov, B. S. J. Costa, and M. Sayed-Mouchaweh, "An overview on fault diagnosis and nature-inspired optimal control of industrial process applications," Computers in Industry, vol. 74, pp. 75-94, 2015.

[4] A. K. S. Jardine, D. Lin, and D. Banjevic, "A review on machinery diagnostics and prognostics implementing condition-based maintenance," Mechanical Systems and Signal Processing, vol. 20, no. 7, pp. 1483-1510, 2006.

[5] W. G. Lee, J. W. Lee, M. S. Hong, S.-H. Nam, Y. Jeon, and M. G. Lee, "Failure diagnosis system for a ball-screw by using vibration signals," Shock and Vibration, vol. 2015, Article ID 435870, 9 pages, 2015.

[6] M. C. Carnera, "Selection of diagnostic techniques and instrumentation in a predictive maintenance program. A case study," Decision Support Systems, vol. 38, no. 4, pp. 539-555, 2005.

[7] Z. Yang, "Automatic condition monitoring of industrial rollingelement bearings using Motor's vibration and current analysis," Shock and Vibration, vol. 2015, Article ID 486159, 12 pages, 2015.

[8] S. T. Mahmood, Use of vibrations analysis technique in condition based maintenance [Ph.D. thesis], Royal Institute of Technology, Stockholm, Sweden, 2011.

[9] J. Qu, Z. Zhang, and T. Gong, "A novel intelligent method for mechanical fault diagnosis based on dual-tree complex wavelet packet transform and multiple classifier fusion," Neurocomputing, vol. 171, no. 1, pp. 837-853, 2016.

[10] B. S. J. Costa, P. P. Angelov, and L. A. Guedes, "Fully unsupervised fault detection and identification based on recursive density estimation and self-evolving cloud-based classifier," Neurocomputing, vol. 150, pp. 289-303, 2015.

[11] G. Yang and H. Liang, "Condition monitoring and fault diagnosis for an antifalling safety device," Shock and Vibration, vol. 2015, Article ID 286781, 12 pages, 2015.

[12] P. A. Delgado-Arredondo, A. Garcia-Perez, D. Morinigo-Sotelo et al., "Comparative study of time-frequency decomposition techniques for fault detection in induction motors using vibration analysis during startup transient," Shock and Vibration, vol. 2015, Article ID 708034, 14 pages, 2015.

[13] T. Rosqvist, "Stopping time optimisation in condition monitoring," Reliability Engineering and System Safety, vol. 76, no. 3, pp. 319-325, 2002.

[14] B. Al-Najjar, "On establishing cost-effective condition-based maintenance: exemplified for vibration-based maintenance in case companies," Journal of Quality in Maintenance Engineering, vol. 18, no. 4, pp. 401-416, 2012.

[15] I. B. Huang, J. Keisler, and I. Linkov, "Multi-criteria decision analysis in environmental sciences: ten years of applications and trends," Science of the Total Environment, vol. 409, no. 19, pp. 3578-3594, 2011.

[16] G. Munda, P. Nijkamp, and P. Rietveld, "Qualitative multicriteria evaluation for environmental management," Ecological Economics, vol. 10, no. 2, pp. 97-112, 1994.

[17] G. Munda, "'Measuring sustainability': a multi-criterion framework," Environment, Development and Sustainability, vol. 7, no. 1, pp. 117-134, 2005.

[18] M. T. Isaai, A. Kanani, M. Tootoonchi, and H. R. Afzali, "Intelligent timetable evaluation using fuzzy AHP," Expert Systems with Applications, vol. 38, no. 4, pp. 3718-3723, 2011.

[19] S. Lee, G. Mogi, S. Lee, and J. Kim, "Prioritizing the weights of hydrogen energy technologies in the sector of the hydrogen economy by using a fuzzy AHP approach," International Journal of Hydrogen Energy, vol. 36, no. 2, pp. 1897-1902, 2011. 
[20] F. T. Bozbura, A. Beskese, and C. Kahraman, "Prioritization of human capital measurement indicators using fuzzy AHP," Expert Systems with Applications, vol. 32, no. 4, pp. 1100-1112, 2007.

[21] M. J. Liberatore and R. L. Nydick, "The analytic hierarchy process in medical and health care decision making: a literature review," European Journal of Operational Research, vol. 189, no. 1, pp. 194-207, 2008.

[22] C. W. de Silva, "Hardware and software selection for experimental modal analysis," Shock and Vibration Digest, vol. 16, no. 8, pp. 3-10, 1984.

[23] C. M. Harris and A. G. Piersol, Harris' Shock and Vibration Handbook, McGraw-Hill, New York, NY, USA, 2002.

[24] C. Scheffer and P. Girdhar, Machinery Vibration Analysis \& Predictive Maintenance, Elsevier, Oxford, UK, 2004.

[25] A. G. Rehorn, J. Jiang, and P. E. Orban, "State-of-the-art methods and results in tool condition monitoring: a review," The International Journal of Advanced Manufacturing Technology, vol. 26, no. 7-8, pp. 693-710, 2005.

[26] R. B. Randall, Vibration-Based Condition Monitoring: Industrial, Aerospace and Automotive Applications, John Wiley \& Sons, Chichester, UK, 2011.

[27] K. E. Holbert and K. Lin, "Nuclear power plant instrumentation fault detection using fuzzy logic," Science and Technology of Nuclear Installations, vol. 2012, Article ID 421070, 11 pages, 2012.

[28] Q. Wang and J. Gao, "Research and application of risk and condition based maintenance task optimization technology in an oil transfer station," Journal of Loss Prevention in the Process Industries, vol. 25, no. 6, pp. 1018-1027, 2012.

[29] J. Ren and M. Lützen, "Fuzzy multi-criteria decision-making method for technology selection for emissions reduction from shipping under uncertainties," Transportation Research Part D: Transport and Environment, vol. 40, pp. 43-60, 2015.

[30] M. Weigel, M. Fischedick, J. Marzinkowski, and P. Winzer, "Multicriteria analysis of primary steelmaking technologies," Journal of Cleaner Production, vol. 112, no. 1, pp. 1064-1076, 2016.

[31] D. Štreimikiene, J. Šliogeriene, and Z. Turskis, "Multi-criteria analysis of electricity generation technologies in Lithuania," Renewable Energy, vol. 85, pp. 148-156, 2016.

[32] S.-P. Wan, F. Wang, and J.-Y. Dong, "A novel group decision making method with intuitionistic fuzzy preference relations for RFID technology selection," Applied Soft Computing, vol. 38, pp. 405-422, 2016.

[33] I. Ivlev, J. Vacek, and P. Kneppo, "Multi-criteria decision analysis for supporting the selection of medical devices under uncertainty," European Journal of Operational Research, vol. 247, no. 1, pp. 216-228, 2015.

[34] H.-C. Liu, J.-X. You, C. Lu, and Y.-Z. Chen, "Evaluating healthcare waste treatment technologies using a hybrid multi-criteria decision making model," Renewable and Sustainable Energy Reviews, vol. 41, pp. 932-942, 2015.

[35] M. C. Carnero and J. C. Hidalgo, "Evaluation of condition based maintenance through activity based cost," Maintenance Journal, vol. 16, pp. 54-61, 2003.

[36] M. C. Carnero, "The control of the setting up of a predictive maintenance programme using a system of indicators," Omega, vol. 32, no. 1, pp. 57-75, 2004.

[37] M. C. Carnero, "An evaluation system of the setting up of predictive maintenance programmes," Reliability Engineering \& System Safety, vol. 91, no. 8, pp. 945-963, 2006.
[38] M. C. Carnero, "Model for the selection of predictive maintenance techniques," INFOR, vol. 45, no. 2, pp. 83-94, 2007.

[39] M. C. Carnero, "Selection of condition monitoring techniques using discrete probability distributions: a case study," Journal of Risk and Reliability, vol. 223, pp. 99-117, 2009.

[40] C. A. Bana e Costa, M. C. Carnero, and M. D. Oliveira, "A multi-criteria model for auditing a Predictive Maintenance Programme," European Journal of Operational Research, vol. 217, no. 2, pp. 381-393, 2012.

[41] T. L. Saaty, The Analytic Hierarchy Process, McGraw-Hill, New York, NY, USA, 1980.

[42] C.-H. Cheng, "Evaluating naval tactical missile systems by fuzzy AHP based on the grade value of membership function," European Journal of Operational Research, vol. 96, no. 2, pp. 343-350, 1997.

[43] H.-C. Liu, J.-X. You, X.-Y. You, and M.-M. Shan, "A novel approach for failure mode and effects analysis using combination weighting and fuzzy VIKOR method," Applied Soft Computing Journal, vol. 28, pp. 579-588, 2015.

[44] Y.-M. Wang, Y. Luo, and Z. Hua, "On the extent analysis method for fuzzy AHP and its applications," European Journal of Operational Research, vol. 186, no. 2, pp. 735-747, 2008.

[45] K.-J. Zhu, Y. Jing, and D.-Y. Chang, "Discussion on extent analysis method and applications of fuzzy AHP," European Journal of Operational Research, vol. 116, no. 2, pp. 450-456, 1999.

[46] L. A. Zadeh, "Fuzzy sets," Information and Computation, vol. 8, pp. 338-353, 1965.

[47] U. Cebeci, "Fuzzy AHP-based decision support system for selecting ERP systems in textile industry by using balanced scorecard," Expert Systems with Applications, vol. 36, no. 5, pp. 8900-8909, 2009.

[48] D.-Y. Chang, "Applications of the extent analysis method on fuzzy AHP," European Journal of Operational Research, vol. 95, no. 3, pp. 649-655, 1996.

[49] A. Kaufmann and M. M. Gupta, Fuzzy Mathematical Models in Engineering and Management Science, North-Holland, Amsterdam, The Netherlands, 1988.

[50] O. Meixner, "Fuzzy AHP group decision analysis and its application for the evaluation of energy sources," in Proceedings of the 10th International Symposium on the Analytic Hierarchy/Network Process, Pittsburgh, Pa, USA, 2009.

[51] F. R. Lima, L. Osiro, and L. C. R. Carpinetti, "A comparison between Fuzzy AHP and Fuzzy TOPSIS methods to supplier selection," Applied Soft Computing Journal, vol. 21, pp. 194-209, 2014.

[52] T. L. Saaty, Decision Making with Dependence and Feedback: The Analytic Network Process, RWS Publications, Pittsburgh, Pa, USA, 2001.

[53] G. Daza, Apuntes del Curso Vibraciones Mecánicas, Universidad Técnica Federico Santa María, 2007.

[54] J. Veldman, W. Klingenberg, and H. Wortmann, "Managing condition-based maintenance technology: a multiple case study in the process industry," Journal of Quality in Maintenance Engineering, vol. 17, no. 1, pp. 40-62, 2011.

[55] F. Ballesteros, "Equipos portátiles de medida de vibración para diagnóstico de maquinaria," Tech. Rep. NT08/2, Preditec-IRM, Zaragoza, Spain, 2014.

[56] A. J. M. Goossens and R. J. I. Basten, "Exploring maintenance policy selection using the analytic hierarchy process; an application for naval ships," Reliability Engineering and System Safety, vol. 142, pp. 31-41, 2015. 
[57] A. Dargi, A. Anjomshoae, M. R. Galankashi, A. Memari, and M. B. M. Tap, "Supplier selection: a fuzzy-ANP approach," Procedia Computer Science, vol. 31, pp. 691-700, 2014.

[58] J. Lee, H. Cho, and Y. S. Kim, "Assessing business impacts of agility criterion and order allocation strategy in multi-criteria supplier selection," Expert Systems with Applications, vol. 42, no. 3, pp. 1136-1148, 2015.

[59] R. Abratt, "Industrial buying in high-tech markets," Industrial Marketing Management, vol. 15, no. 4, pp. 293-298, 1986.

[60] R. L. Keeney, Value-Focused Thinking: A Path to Creative Decision Making, Harvard University Press, Cambridge, Mass, USA, 1996.

[61] C. A. Bana e Costa, É. C. Corrêa, J.-M. De Corte, and J.-C. Vansnick, "Facilitating bid evaluation in public call for tenders: a socio-technical approach," Omega, vol. 30, no. 3, pp. 227-242, 2002.

[62] C. L. Hwang and K. Yoon, Multiple Attribute Decision Making: Methods and Applications. A State-of-the-Art Survey, vol. 186 of Lecture Notes in Economics and Mathematical Systems, Springer, New York, NY, USA, 1981.

[63] C.-T. Chen, "Extensions of the TOPSIS for group decisionmaking under fuzzy environment," Fuzzy Sets and Systems, vol. 114, no. 1, pp. 1-9, 2000.

[64] C. Kahraman, S. C. Onar, and B. Oztaysi, "Fuzzy multicriteria decision-making: a literature review," International Journal of Computational Intelligence Systems, vol. 8, no. 4, pp. 637-666, 2015.

[65] F. Uysal and Ö. Tosun, "Fuzzy TOPSIS-based computerized maintenance management system selection," Journal of Manufacturing Technology Management, vol. 23, no. 2, pp. 212-228, 2012.

[66] Y. O. Ouma, J. Opudo, and S. Nyambenya, "Comparison of fuzzy AHP and fuzzy TOPSIS for road pavement maintenance prioritization: methodological exposition and case study," Advances in Civil Engineering, vol. 2015, Article ID 140189, 17 pages, 2015. 


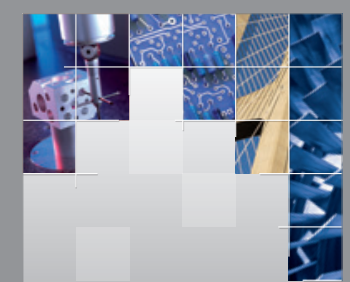

\section{Enfincering}
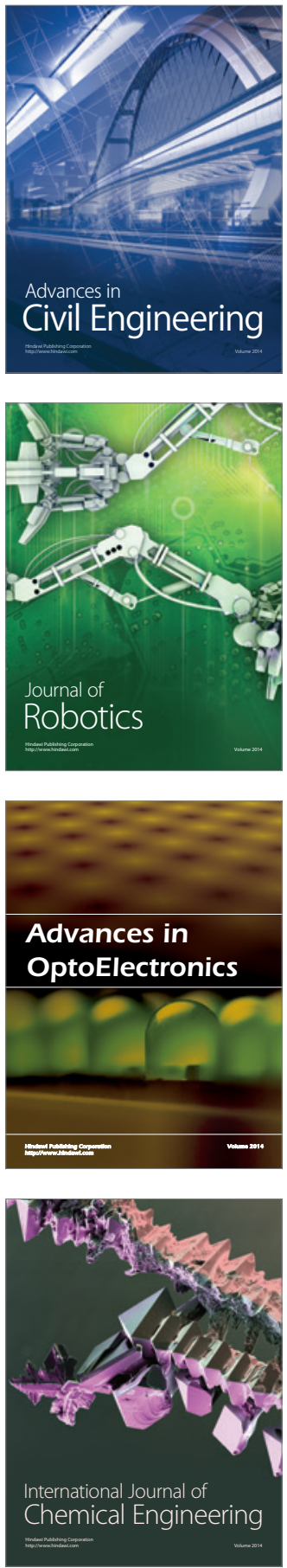

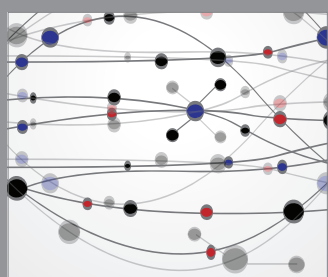

The Scientific World Journal

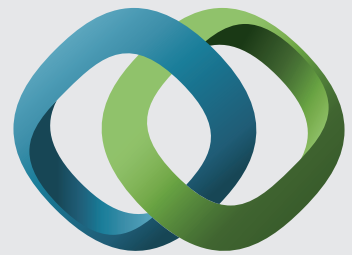

\section{Hindawi}

Submit your manuscripts at

http://www.hindawi.com
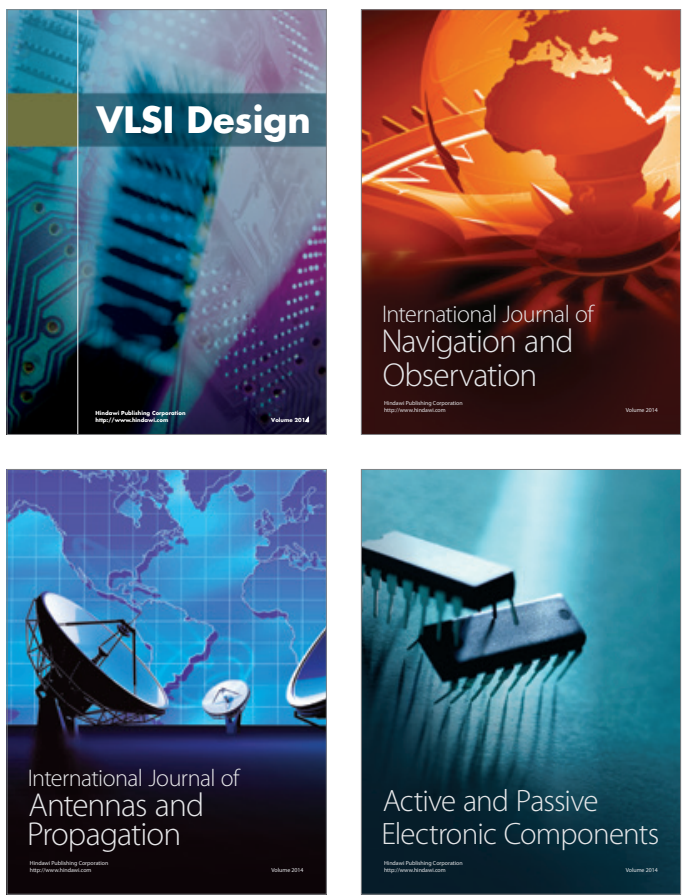
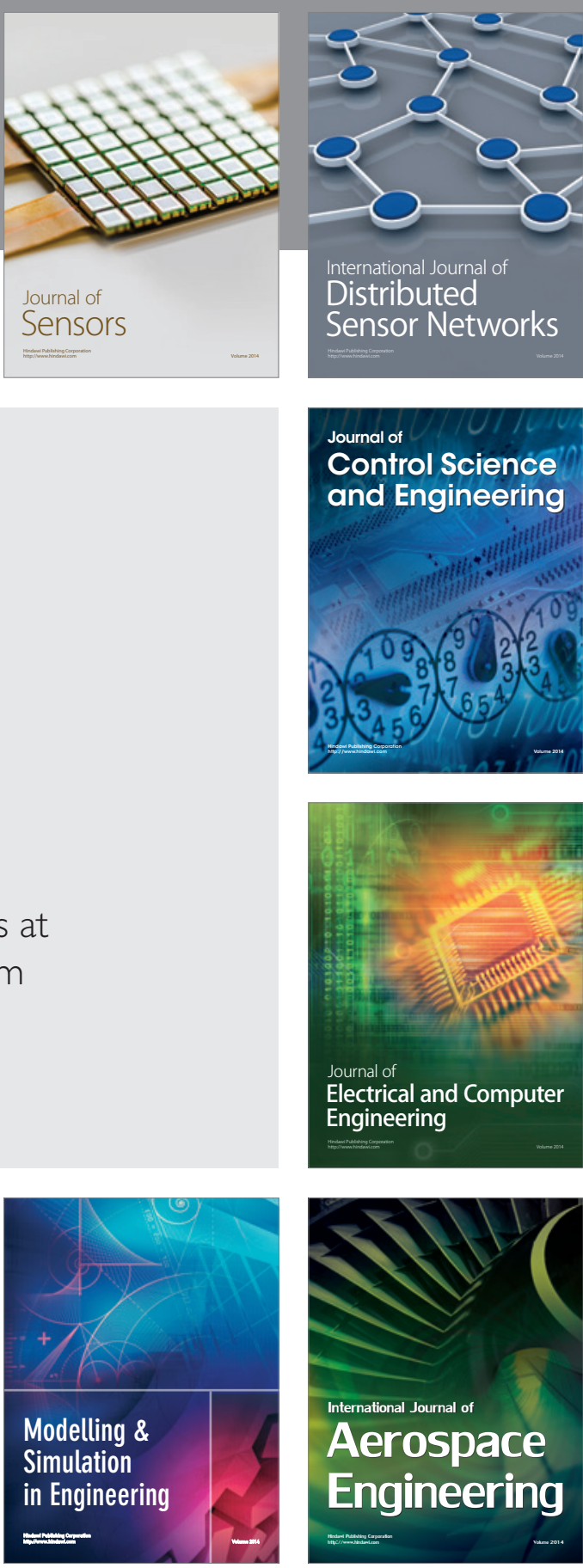

International Journal of

Distributed

Sensor Networks

Journal of

Control Science

and Engineering
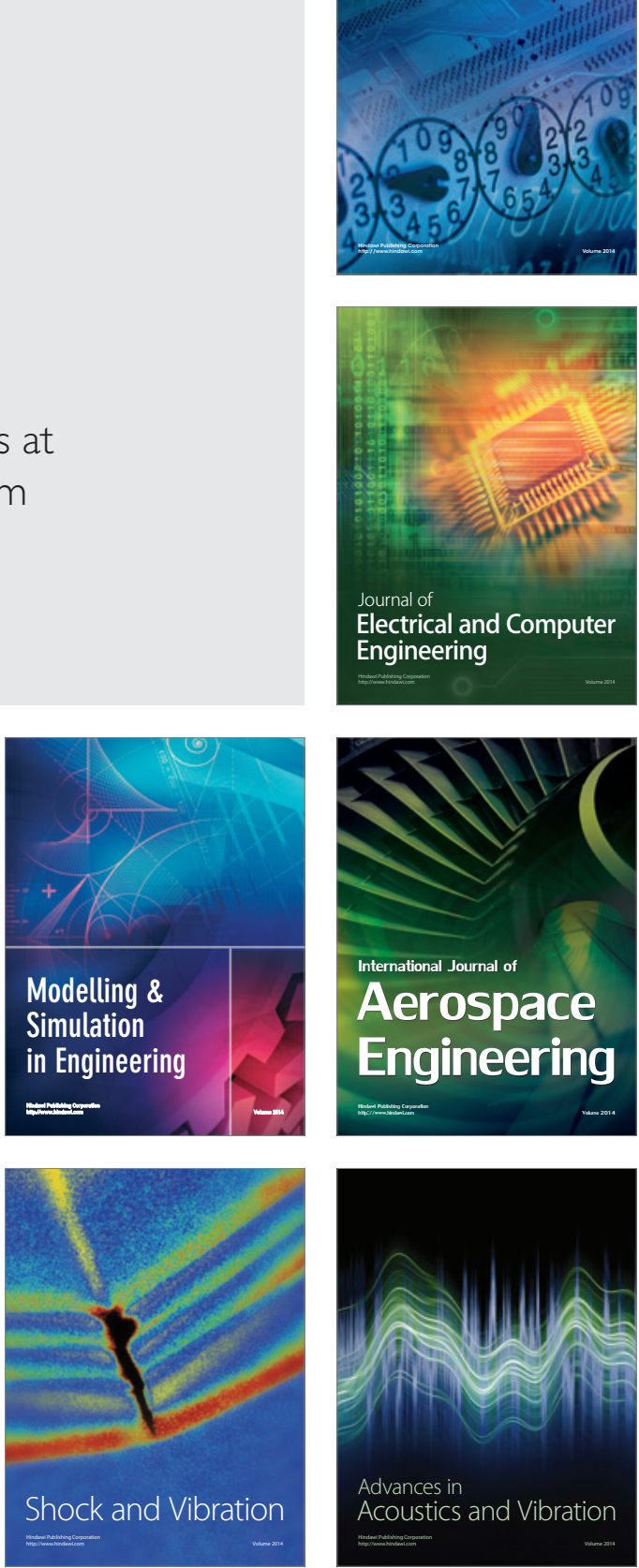